\title{
Saphenous vein graft aneurysm
}

Amyn Malik MD, Yaqoob Mohyuddin MD, Peter Chien MD, Arshad Yekta MD

A

64-year-old Caucasian man with a history of hypertension, diabetes, Raynaud's phenomenon and coronary artery bypass grafting presented with chest pain and syncope. The echocardiogram revealed an extracardiac mass (arrow) with compression of the atrium (Figure 1). The cardiac computed tomographic angiogram revealed an $8 \mathrm{~cm}$ right coronary artery saphenous vein graft (SVG) aneurysm that was occluded in its mid segment (Figure 2). The aneurysm was lined with thrombus. The coronary angiogram confirmed the above findings (Figure 3). The patient subsequently underwent resection of the aneurysm, reconstruction of the right atrial wall and redo saphenous vein bypass graft to the right coronary artery. He did well postoperatively.

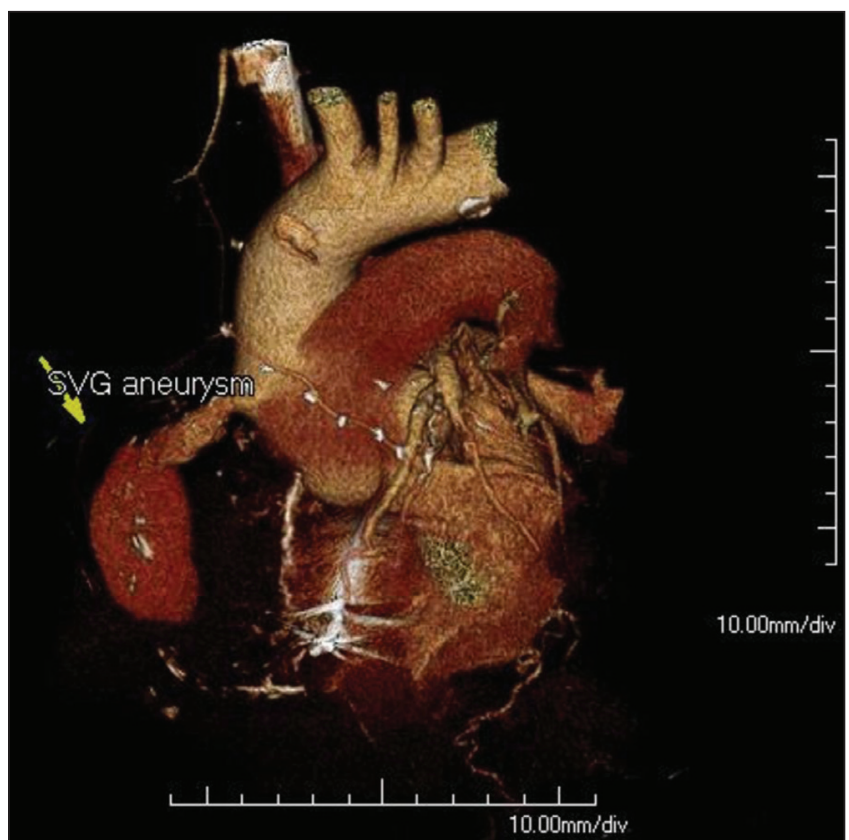

Figure 2

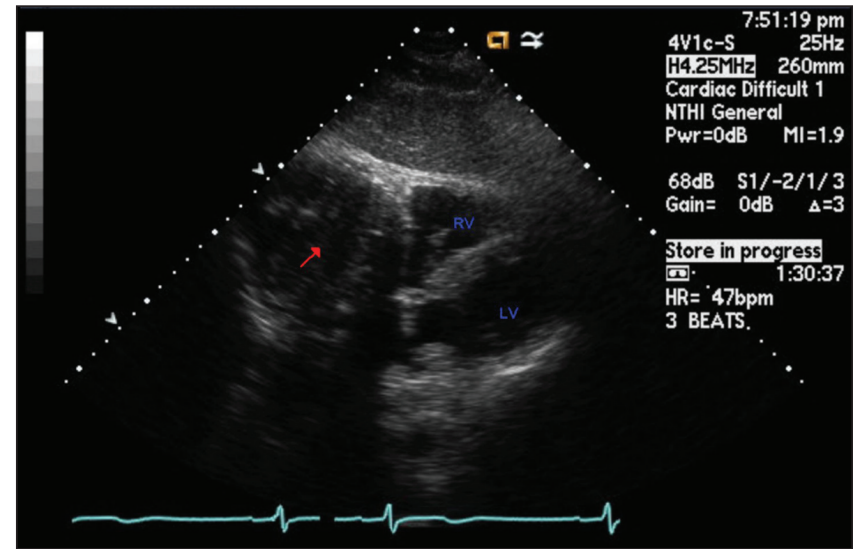

Figure 1) LV Left ventricle; RV Right ventricle

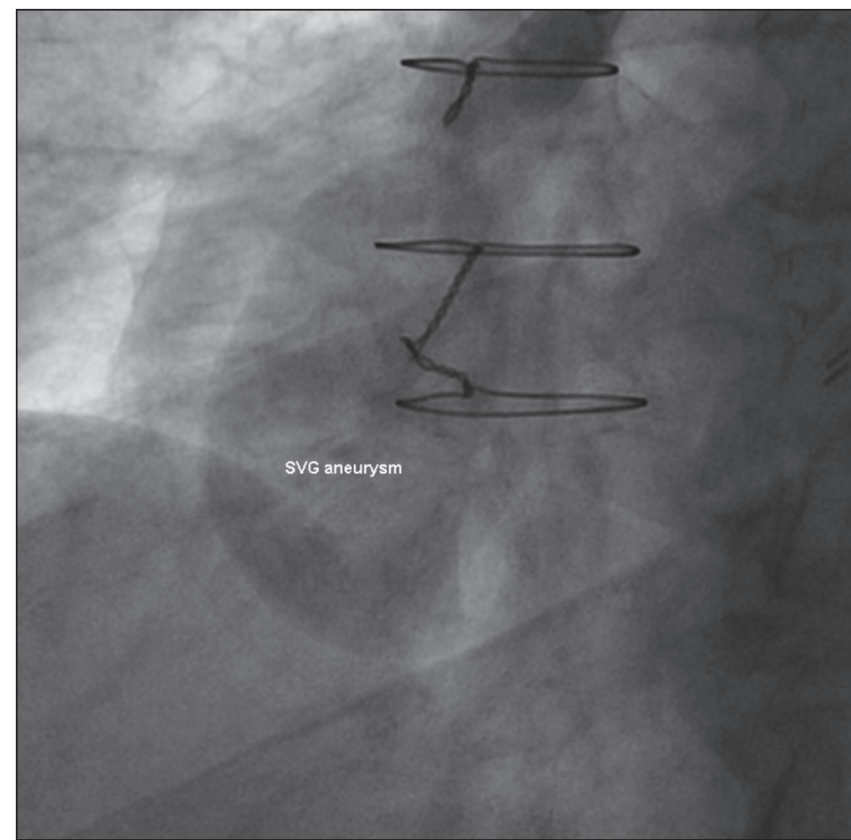

Figure 3

Henry Low Heart Center, Hartford, Connecticut, USA

Correspondence and reprints: Dr Amyn Malik, Hartford Hospital, 85 Seymour Street, Hartford, Connecticut 06102, USA. Telephone 860-545-5020, fax 860-545-5631, e-mail amynmalik2001@yahoo.com

Received for publication May 6, 2009. Accepted May 24, 2009 